\title{
Revolución Verde, neoliberalismo y transgénicos en México: hacia una subordinación del maíz al capital
}

\author{
Green Revolution, neoliberalism and transgenic crops in Mexico: \\ towards a subordination of corn to capital
}

Fleur Gouttefanjat

Sciences Po - Instituto de Estudios Políticos de París, Francia

Correo: fleur.gouttefanjat@gmail.com

Resumen: Durante todo el siglo XX se ha venido gestando un largo proceso de trastrocamiento de los patrones de producción y consumo de alimentos en México, en el cual el cultivo tradicional del maíz nativo ha sido particularmente afectado. El presento artículo pretendió analizar tal movimiento de degradación mediante los recursos teóricos de la crítica de la economía política. Para tal cometido, se empleó una metodología cualitativa en la cual se analizaron tres grandes momentos de cambios en la agricultura mexicana - Revolución Verde, políticas neoliberales e introducción de cultivos transgénicos de maíz — mediante el concepto de subsunción real del consumo al capital. Los datos examinados fueron obtenidos a partir del análisis documental de varias investigaciones científicas encontradas en distintas bases de datos alrededor del maíz y de los cambios en sus técnicas de cultivo. Los resultados arrojaron que estos tres momentos conllevaron importantes transformaciones en la producción del maíz a favor de las grandes corporaciones transnacionales vendedoras de semillas y de insumos químicos y en provecho de un modelo industrial basado en la búsqueda de ganancias. Las transformaciones en el proceso productivo generaron una degradación de la salud de los consumidores y de los productores y una contaminación de los entornos naturales, características del desarrollo histórico capitalista.

Palabras clave: maíz; neoliberalismo; Revolución Verde; subsunción real del consumo al capital; transgénicos

\begin{abstract}
The twentieth century has been marked by structural modifications in cultivation techniques and food consumption trends, in which the traditional culture of native corn has been particularly affected. The purpose of this article is to analyze this phenomenon thanks to the critique of political economy. To that aim, we used a qualitative methodology in which we examined three moments of great changes in Mexican agriculture - the Green Revolution, the implementation of neoliberal politics and the introduction of transgenic corn crops - from the concept of subsomption of the consumption process by capital (Veraza). The data were obtained thanks to the analysis of scientific investigations about maize cultivation founded in several databases. The results achieved outlined a shift in corn production in favor of transnational food corporations and for the benefit of an industrial model based on the pursuit of profits. This alteration in the productive process created health and environmental issues that are typical of the contemporary capitalist development.
\end{abstract}

Keywords: corn; Green Revolution; neoliberalism; subsomption of the consumption process by capital; transgenic crops

Gouttefanjat, F. (2021). Revolución Verde, neoliberalismo y transgénicos en México: hacia una subordinación del maíz al capital. [Green Revolution, neoliberalism and transgenic crops in Mexico: towards a subordination of corn to capital]. Forhum International Journal of Social Sciences and Humanities, 3(4), 108-119. https://doi.org/10.35766/j.forhum2021.04.03.9

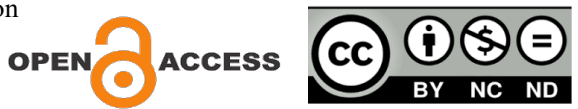




\section{Introducción}

Se conoce como "Revolución Neolítica" el periodo histórico que corresponde a los comienzos de la agricultura humana, ya que el trabajo agrícola representó un verdadero paso hacia delante para el despliegue de las sociedades humanas (Álvarez-Buylla \& Piñeyro, 2013). Eso se debió principalmente al hecho de que empezaron a cultivarse en este momento diversos cereales que aumentaron la cantidad de energía al alcance de los seres humanos (Cubero, 2018). Todas las civilizaciones importantes del pasado se estructuraron en torno al cultivo principal de un cereal que articuló no solamente su sistema alimentario, sino que, también, el desarrollo de sus fuerzas productivas (Echeverría, 2010; Cuevas, 2014).

Hoy asistimos a cambios profundos en los patrones alimentarios. Los cereales en su forma integral se encuentran cada vez más marginados y/o destinados a consumo animal mientras que se expande el consumo de harinas refinadas. Además, la carne y el azúcar adquieren un papel cada vez más central en la alimentación humana (Bertran, 2017; Jardí et al., 2019; Cruz et al., 2020); lo que Veraza (2007) consideró como un síntoma del despliegue histórico del modo de producción capitalista basado en la explotación de la fuerza de trabajo y el productivismo.

El maíz no escapa a dicho fenómeno global y es, incluso, por su papel central en la industria alimentaria y en la producción de piensos (González, 2008), particularmente afectado. Las consecuencias de este proceso, negativas tanto para productores como consumidores, han sido ampliamente documentadas (De Ita, 2013; Colectivo por la autonomía, 2014; Sandoval, 2017; CerrosChávez, 2017) y subrayaron "un ataque sistemático e intencional a la existencia del maíz, a la subsistencia de los pueblos y comunidades y a su autonomía" (Colectivo por la autonomía, 2014, p.258).

El presente artículo busca precisar el análisis de este fenómeno desde la crítica de la economía política, particularmente desde los conceptos de subsunción del proceso productivo (Marx, 2005) y subsunción del proceso consuntivo (Veraza, 2008) al capital. Es decir, que se pretende analizar la degradación del maíz nativo y de sus métodos de cultivo dentro del marco del desarrollo histórico del modo de producción capitalista concebido como despliegue de la contradicción entre un proceso de producción de valores de uso y un proceso de acumulación de capital.

El artículo pretende, por ende, cumplir con dos objetivos entrelazados y complementarios:

1. Recuperar y ejemplificar la teoría de la subsunción real del consumo bajo el capital (Veraza, 2008) para dar cuenta del desarrollo histórico capitalista en el siglo XX como continuidad con lo que Marx había definido como subsunción formal y real del proceso de trabajo inmediato al capital (2005). Con ello, se busca abonar a la tesis de una validez de la teoría de Marx para el análisis de la sociedad contemporánea.

2. Analizar la degradación del maíz nativo de una manera integral, examinándola como un proceso y conectándola con el desarrollo del modo de producción actual en su conjunto. Tal objetivo implica identificar los distintos elementos que constituyeron este proceso.

\section{Materiales y método}

El presente trabajo es de tipo teórico y descansa sobre una estrategia metodológica cualitativa en la cual se articulan conceptos propios de la crítica de la economía política con datos de índole 
económica, histórica y política acerca de los cambios ocurridos en la agricultura mexicana durante el siglo $\mathrm{XX}$.

El principal concepto crítico aquí empleado es el de subsunción real del consumo al capital desarrollado por Veraza (2005) para pensar el desarrollo histórico capitalista durante el siglo XX en continuidad con lo que Marx había formulado acerca del modo de producción capitalista un siglo antes. Para tal cometido, Marx desarrolla los conceptos de subsunción formal y real del proceso de trabajo bajo el capital, con los cuales opera un tratamiento riguroso del proceso de trabajo y de la manera con la cual éste se encuentra sometido a las necesidades de acumulación del capital. Muestra así como este dominio fue primero formal — sin cambiar nada a la estructura interna del trabajo- y luego real con la llamada Revolución Industrial y los cambios técnicos que posibilitó. El objetivo de Jorge Veraza a la hora de hablar de subsunción real del consumo al capital, es indicar cómo la subsunción real del proceso de trabajo al capital propició la constitución de un cuerpo productivo específicamente capitalista cuyos resultados — los bienes de consumo - están por consiguiente también estructurados materialmente de acuerdo a los imperativos del capital. Por este medio, quiere decir que estos bienes adquieren un fin adecuado a la extracción de plus valor y se presentan por ende como objetos nocivos para la salud humana, testificando de una modificación negativa del soporte material de la riqueza.

Con el objetivo de aplicar este concepto al análisis del proceso histórico de degradación del maíz nativo transcurrido durante el siglo $\mathrm{XX}$, se estudiaron aquí tres grandes momentos que transformaron las prácticas agrícolas mexicanas apuntando al desplazamiento o al trastrocamiento del cultivo del maíz: la Revolución Verde, la implementación de políticas neoliberales y la liberación de maíz transgénico en México. El examen de estos tres fenómenos se nutrió de varios trabajos científicos alrededor del maíz, de la evolución de sus técnicas de cultivo y de los padecimientos que sufre el campo mexicano. Todas estas investigaciones fueron encontradas en bases de datos como Scopus, Dialnet Métricas y Redalyc. Además, se recurrió también a notas de periódico e informes de organizaciones cercanas al campo mexicano como el Centro de Estudio para el Cambio en el Campo Mexicano (CECCAM) o el Grupo de Acción sobre Erosión, Tecnología y Concentración (Grupo ETC). Esta revisión bibliográfica permitió la constitución de fichas temáticas que fueron destinadas a clasificar los distintos cambios que enfrentó el cultivo del maíz nativo.

\section{Resultados}

La Revolución Verde como primer paso de la subsunción real del sector agrícola al capital

El primer embate del agronegocio contra la agricultura campesina tradicional, y especialmente contra el maíz, empezó con la llamada Revolución Verde, implementada en varios países del Sur del planeta en la segunda mitad del siglo XX y en la cual México tuvo un lugar destacado.

Esta "revolución", diseñada en Estados Unidos, abarcó tanto la investigación respecto al aumento de la productividad de las plantas como la puesta en práctica de distintas técnicas de cultivo basadas en el uso masivo de agroquímicos y en la mecanización de tipo industrial. No obstante, su aspecto descollante ha sido la experimentación sobre semillas y la creación y comercialización de semillas híbridas, producidas en laboratorio sobre la base de cruzamientos entre variedades de una misma planta (Méndez, 2017). En este momento, se inauguró por ende la mercantilización del primer insumo de los campesinos que son las semillas y se modificaron los patrones tradicionales de cultivo 
a escala mundial a favor de los grandes sistemas agroalimentarios dedicados a la producción alimentaria industrial y de forraje.

Si bien este proyecto ha sido presentado históricamente como una iniciativa filantrópica de lucha contra el hambre por las fundaciones que la apoyan — Ford y Rockefeller-, se han subrayado sus fines comerciales (Méndez, 2017) y geopolíticos (Picado, 2008) prioritarios. Respecto al aspecto comercial, Méndez (2017) subrayó por ejemplo la oportunidad que vieron las grandes empresas productoras de semillas estadounidenses en expandir su mercado en el marco de la post segunda Guerra Mundial. Sin embargo, ya que las semillas tienen "distintos parámetros de germinación, crecimiento y producción que dependen de las condiciones del ambiente en dónde se cultivan" (Méndez, 2017: 140), estas empresas tuvieron que pactar con agencias transnacionales y gobiernos nacionales proyectos de "modernización agrícola" que tenían en realidad como objetivo asegurar las exportaciones mediante la experimentación local.

Ahora bien, cabe decir que si el gran despliegue de la Revolución Verde ocurrió en los años 1960 — cuando las semillas híbridas se multiplican en Asia del Suroeste y en la India — dio en realidad sus primeros pasos en la década de los cuarenta en México (Picado, 2008). En efecto, en este periodo, el contexto nacional mexicano era propicio para este tipo de proyecto ya que como consecuencia del modelo de industrialización por sustitución de importaciones entonces en vigor, se intentaba modernizar el ámbito agrícola (Picado, 2008). En 1941, se firmó así un acuerdo entre la fundación Rockefeller y el gobierno mexicano, mediante su Secretaría de Agricultura, para la investigación en torno a mejora de los rendimientos agrícolas y a la experimentación sobre trigo y maíz en territorio mexicano. Desempeñó un papel clave en este convenio el entonces vicepresidente de Estados Unidos Henry A. Wallace, también accionista importante de la gran empresa de semillas híbridas Pioneer HiBred Company (Picado, 2008). Dos años después, fueron creadas la Oficina de Estudios Especiales - que recibía importantes financiamientos de la fundación Rockefeller y se beneficiaba de una condición jurídica casi autónoma (Picado, 2008) - y el Programa en Ciencias Agrícolas, ambos encargados de gestionar el proceso de experimentación. Finalmente, surgió en 1961 el Centro Internacional de Mejoramiento de Maíz y Trigo (CIMMYT) dedicado a la investigación, pero sobre todo a la expansión mundial de los programas de la Revolución Verde, la cual funcionó relativamente bien ya que fueron creados numerosos espacios similares a lo ancho del globo (Luna, Luna \& Sánchez, 2013).

Los primeros resultados del trabajo de hibridación propiamente dicho salieron a partir de 1943 pero tuvieron poco éxito hasta 1953, año en el cual se elaboró finalmente una variedad híbrida de trigo enano que permitió un auge considerable de los rendimientos en las regiones del Norte del país, en los primeros años al menos (Picado, 2008). Durante este periodo, el maíz todavía no ocupó el centro de atención por ser un cultivo de tipo familiar, de pequeño tamaño y con pocos recursos, lo que imposibilitaba la compra por parte de los campesinos del paquete tecnológico con el cual eran vendidas las semillas híbridas. Además, por tratarse de zonas de domesticación del maíz, los campesinos se sentían comprometidos con sus métodos tradicionales de cultivo y sus semillas nativas (Arslan, 2011) y opusieron resistencia a la compra de nuevos insumos de tipo industrial. Por este motivo, la experimentación sobre el maíz tuvo aparentemente pocos efectos sobre la agricultura campesina en estos años, aunque se intentó forzar la difusión de semillas híbridas de maíz tanto por vías formales — mediante la Comisión Nacional del Maíz creada en 1947 por ejemplo- como informales a través de la entrega a grupos privados (Enciso, 2007).

Sin embargo, si bien el cultivo de maíz no fue directamente afectado, padeció la desviación de la mayoría de los financiamientos estatales hacia la agricultura industrial en el Norte del país, muy 
necesitada de complejas infraestructuras de riego por tratarse de regiones desérticas (Colectivo por la autonomía, 2014). Además, los experimentos sobre el trigo abrieron claramente la puerta a la multiplicación de técnicas de cultivo diseñadas por las grandes corporaciones estadounidenses y basadas en la mecanización y los insumos químicos. Estos métodos se extendieron finalmente al cultivo de maíz en los años ochentas.

Este proceso fomentó la concentración del comercio agroalimentario en detrimento de los pequeños cultivadores y la uniformidad de los métodos de cultivo (Gasca \& Torres, 2014; Jönsson, 2016). En este marco, la agricultura campesina disminuyó y se produjo un fuerte éxodo rural. Se contaminaron también masivamente los suelos por el uso de agroquímicos (Moreno, 2017) y se redujo la cualidad nutricional de los alimentos por cosecha mecanizada (Romero, Tona, Ruiz, Ávila \& Alezones, 2018) generando el problema conocido como el "hambre oculto" (Ribeiro, 2009). Finalmente, el cultivo de maíz bajo riego fomentado por la Revolución Verde en regiones desérticas del Norte de México no permitió hasta la fecha tener mejores rendimientos que los cultivos de temporal, además de ser muy costosos para el medioambiente (Montesillo-Cedillo, 2016). En este marco se puede hablar no solamente de una subsunción del consumo final - destinado directamente al consumidor - sino también del consumo llamado "productivo" ya que abarca todos los bienes que sirven de premisa al proceso de producción : semillas, tierras, biodiversidad, etc.

Este proceso histórico de degradación del entorno natural y de sumisión de la producción y del consumo agrícola al capital se encontró potenciado a finales del siglo XX, apoyado por las políticas neoliberales implementadas en México. En efecto, aunque permeaban los intereses de firmas transnacionales, la Revolución Verde tenía como principales actores a los Estados nacionales. Al contrario, con la entrada a la llamada era neoliberal, el mercado mundial globalizado y encabezado por Estados Unidos pasó a ser el referente principal de toda la producción agrícola, dejando la soberanía nacional en mano de intereses privados y/o extranjeros (Veraza, 2008).

\section{El neoliberalismo como consolidación de la subsunción real del sector agrícola al capital}

El neoliberalismo puede ser definido como una serie de medidas, principalmente económicas, destinadas a paliar la caída de la tasa de ganancia, sobre todo, después de la crisis de 1971, mediante la instauración de un nuevo modelo particular de acumulación distinto al modelo keynesiano (Harvey, 2007). Este nuevo patrón fue pensado principalmente por la sociedad del Mont Pélerin —entre cuyos miembros destacan Milton Friedman y Friedrich Hayek - e impuesto a los pueblos mediante gobiernos e instancias internacionales. En términos concretos, se trató de liberalizar el comercio mediante la disminución del papel del Estado en la regulación de los asuntos económicos. Dicho de modo aún más concreto, se apuntó hacia la supresión de las barreras que enmarcaban la explotación de los trabajadores y de los recursos naturales a nivel nacional (Harvey, 2007). Bajo una apariencia de apología del buen funcionamiento del mercado y de las libertades individuales, el patrón de acumulación neoliberal conformó en realidad un sistema jerarquizado de privilegios, en colusión con el Estado o de manera extralegal (Veraza, 2015). Así, más que un rechazo total de la entidad estatal, el neoliberalismo corresponde a una reconfiguración de sus prerrogativas, sobretodo en lo que tiene que ver con el Estado de bienestar.

En los países del Sur, la implementación de tales medidas se dio principalmente mediante la multiplicación de tratados de libre comercio con potencias del Norte. El periodo neoliberal se caracterizó en efecto por la proliferación de tratados comerciales internacionales dedicados al desmantelamiento de la soberanía internacional y del Estado de derecho en provecho de las grandes 
corporaciones privadas (Colectivo por la autonomía, 2014). En este marco, se llevó a cabo una privatización creciente de ciertos recursos que eran considerados bienes comunes - como el agua o el subsuelo-, elementos que son también premisas naturales de la producción (McCarthy, 2004). Con ello, se radicalizó la subsunción del consumo productivo al capital.

En México, las políticas neoliberales fueron puestas en práctica a partir de 1982, aunque Rajchenberg (2017) ubicó sus orígenes en la oposición al cardenismo y al reparto agrario de principios del siglo XX. Dichas políticas apuntaron a la liberalización del comercio y al retiro del Estado como actor clave de la regulación del mercado (Cabrera, 2015), lo que favoreció sobre todo a las grandes empresas transnacionales (Nápoles, 2017), ya que no se cumplieron las expectativas en términos de empleo y crecimiento económico general (Lomeli \& Vázquez, 2016; Odisio, 2017). En el ámbito político, este movimiento quedó plasmado en la formación de una elite dedicada al despojo en vez de servir el interés publico (Salas-Porras, 2014).

En lo que respecta al sector agrícola, el periodo neoliberal en México fue marcado primero por el fin del apoyo financiero gubernamental al campo. Si bien la mayoría de los créditos estatales ya eran destinados a la producción agrícola industrial, subsistían algunos a favor de los pequeños productores que fueron cancelados bajo el sexenio de Miguel de la Madrid (Colectivo por la autonomía, 2014). En 1992, Carlos Salinas siguió con la misma dinámica al llevar a cabo una reforma del artículo 27 de la Constitución mexicana, lo que permitió la puesta en venta de tierras ejidales (Cabrera, 2015).

La firma del Tratado de Libre Comercio de América del Norte (TLCAN) en 1993 vino a institucionalizar estas reformas estructurales en curso mediante un ataque brutal a los derechos y bienes colectivos que representó cambios drásticos para el campo mexicano (De Ita, 2013). En apenas algunos años, resaltó la importancia que tuvo el maíz a la hora de firmar el tratado entre Estados Unidos, México y Canadá. En efecto, si bien el gobierno mexicano prometió la liberalización del comercio de este producto sobre un plazo de 15 años y su protección por parte del Estado durante este periodo, realizó ya en los primeros años un agresivo dumping social contra los productores mexicanos al cancelar aranceles y cuotas de importación. Con la entrada masiva de maíz importado de Estados Unidos — cuyo cultivo estaba siendo apoyado por el propio gobierno estadounidenselos pequeños productores mexicanos no pudieron sostener la competencia y la producción y los mercados fueron rápidamente acaparados por las corporaciones transnacionales (De Ita, 2013). La producción de maíz se dirigió cada vez más hacia una producción industrial basada en el modelo norteamericano heredado de la Revolución Verde, en detrimento de las pequeñas unidades de producción destinadas al autoconsumo, mientras que la importación de maíz extranjero siguió aumentando (De Ita, 2013). En este marco, el precio del maíz cayó brutalmente en el mercado interno (González, 2014), lo que condujo numerosos campesinos a la ruina, en provecho de grandes empresas como Cargill, Tyson, Pilgrims o Corn Products International.

El proceso en su conjunto fomentó una destrucción de la soberanía alimentaria que fue explicada y justificada por las necesidades del comercio internacional y las ventajas comparativas. En realidad, más que la mano invisible del mercado, fueron las políticas domésticas las responsables de la evolución de este sector agrícola (Sweneey et al., 2013; Eakin et al., 2018), sobre todo las que tuvieron que ver con la internacionalización neoliberal de la economía (Appendini, 1994). También fueron determinantes los supuestos programas sociales que no cumplieron con los objetivos establecidos - como fue el caso del Programa de Apoyos Directos al Campo (Zarazua-Escobar, Almaguer-Vargas \& Ocampo-Ledesma, 2011) o de la Cruzada contra el Hambre (Huesca, López \& Palacios, 2016) — o que tenían como meta clara la socavación de la pequeña agricultura como el 
Programa de Certificación de Derechos Ejidales y Titulación de Solares Urbanos (Hernández-Santos et al., 2006). En los años posteriores a la ratificación del TLCAN, se desmantelaron igualmente organizaciones e instituciones que apoyaban la pequeña agricultura en México como la Conasupo en 1996, organismo que regulaba los mercados de productos básicos, o la Productora Nacional de Semillas (Pronase) en 2002 (Colectivo por la autonomía, 2014).

El neoliberalismo en México y el TLCAN en particular tuvieron también impactos fuertes sobre el consumidor ya que fueron relacionados con la disminución del consumo promedio de maíz por parte de la población mexicana $\mathrm{y}$, de manera correlativa, con el aumento del consumo de comida chatarra (Cabrera et al., 2019). Eso se debió principalmente al hecho de que creció la presencia de empresas estadounidenses en la producción, el procesamiento y el consumo alimentario en el marco de estas políticas de liberalización de la economía. Tuvo como consecuencia principal el disparo de la obesidad y del sobrepeso (Sánchez-García, Reyes-Morales \& González-Unzaga, 2014) así como la proliferación de enfermedades (Moreno-Altamirano et al., 2014).

Por consiguiente, las políticas neoliberales impuestas en México llevaron a cabo una ampliación cuantitativa y cualitativa de la subordinación del proceso de producción y de consumo de alimentos al capital que ya venía ocurriendo desde la Revolución Verde. Además, la apertura del comercio sirvió de puerta de entrada a los transgénicos en México mediante las importaciones de maíz estadounidense, con lo cual quedó redimensionada la subsunción real del sector agrícola y del consumo alimenticio al capital.

\section{La biotecnología agrícola como redondeamiento de la subsunción real del sector agrícola al capital}

Se llaman transgénicos a organismos cuyo ADN fue modificado por la agregación de unos genes provenientes de otra especie, a veces muy alejada en la escala evolutiva, lo que los distingue de plantas que intercambian genes naturalmente. Además, los organismos genéticamente modificados se diferencian por la rapidez con la cual ocurre el proceso, así como por el desconocimiento de los efectos a mediano y largo plazo de cruces entre especies muy distintas (Álvarez-Buylla \& Piñeyro, 2013; Rendón-Aguilar et al., 2019). De tal manera, la multiplicación de OGMs fue caracterizada por la falta de respeto al principio de precaución y por la ausencia de estudios rigurosos respecto a sus efectos nocivos. Asimismo, y aunque fueron promovidos con argumentos como la mejora de la nutrición humana o el desarrollo de una agricultura más limpia, el cultivo de transgénicos fue responsable de un fuerte auge del uso de glifosato, aunque no se pudo probar un aumento significativo de los rendimientos que lo justificaba (Álvarez-Buylla \& Piñeyro, 2013).

México es uno de los primeros países en los cuales se solicitaron experimentos con transgénicos a finales de los ochentas y desde este momento el país ha favorecido generalmente la libre circulación de aquellos (González, 2019). Las primeras experimentaciones con maíz transgénico tuvieron lugar en 1993 y fueron a cargo del Centro de Investigación y de Estudios Avanzados (CINVESTAV) y del CIMMYT. Frente a la explosión de solicitudes por parte de estos dos organismos en los años siguientes, el Comité Nacional de Bioseguridad Agrícola creó una moratoria a la siembra de maíz transgénico que entró en vigor a partir de 1999 con el objetivo de resguardar las variedades nativas de esta planta en su centro de origen. Sin embargo, continuaron los experimentos de OGMs de otras plantas como el algodón, por ejemplo — a pesar de que México sea también su centro de origen-y siguieron llegando solicitudes para siembra de maíz transgénico, autorizado sobre una pequeña superficie (menos de una hectárea) y con la presencia de barreras físicas y biológicas. En este marco, se probaron siembras de maíz Bt y de maíz resistente a glifosato y glufosinato (Sandoval, 2017). 
Un gran avance para las corporaciones estadounidenses vendedoras de semillas genéticamente modificadas fue la ratificación de la Ley de Bioseguridad — también llamada comúnmente Ley Monsanto - en el 2005 (Ribeiro, 2008) y la actualización de su Reglamento en el 2009. Según Sandoval (2017), tal ley "definió la forma como actualmente se regulan típicamente las actividades de uso confinado y liberación de transgénicos al ambiente, así como su comercialización, importación y exportación" (Sandoval, 2017: 5). Entre otras cosas, acotó por ejemplo los territorios considerados como Centros de Origen y Diversificación Genética del Maíz (CODGM), lo que de manera correlativa permitió la ubicación de espacios en los cuales se podría sembrar maíz genéticamente modificado, por no tratarse de CODGM. A consecuencia de esta ley, se solicitaron entre 2005 y 2017 más de 300 autorizaciones para maíz transgénico (Sandoval, 2017). Además, la ley de Bioseguridad fue acompañada de la Ley de Producción, Certificación y Comercialización de Semillas del 2007 que criminalizó el libre intercambio milenario de semillas, apuntalando el control de las grandes corporaciones sobre el mercado de semillas (Colectivo por la autonomía, 2014).

En 2009 y después de un encuentro con el presidente de Monsanto en Suiza, el ex presidente de México Felipe Calderón puso fin a la moratoria en torno a la siembra de maíz transgénico, con lo cual permitió que fuera considerado legalmente como cualquier otra planta a pesar de tratarse de su centro de origen y diversificación. Como consecuencia, se pidieron numerosas autorizaciones para siembra comercial de maíz por parte de empresas como Monsanto, PHI-Pionner y Dow AgroSciences hasta el 2012 (Sandoval, 2017), fecha en la cual quedaron detenidas por la amplia movilización nacional e internacional en defensa del maíz nativo (Colectivo por la autonomía, 2014).

Además de los efectos negativos de los OGMs y plaguicidas afines sobre la salud de productores y consumidores (efectos alérgenos, enfermedades del sistema endocrino, abortos espontáneos, cánceres y malformaciones congénitas) y el medioambiente, los actores en lucha para la protección y el cuidado del maíz nativo resaltaron también el gran problema que representaron frente a la polinización abierta del maíz (Álvarez-Buylla \& Piñeyro, 2013). En efecto, al contrario de otros cereales como el arroz o el trigo que se autopolinizan, el maíz se caracteriza por un flujo genético continuo, lo que permitió la gran diversidad de maíces hoy existentes pero que facilitó también su contaminación transgénica masiva.

Así, en el 2001, fue registrada la primera contaminación de maíces nativos por OGMs en el estado de Oaxaca por los universitarios I. Chapela y D. Quist (Quist \& Chapela, 2001), lo que fue confirmado posteriormente por análisis de la Comisión Nacional de Biodiversidad (Conabio) y del Instituto Nacional de Ecología. Se estableció en este momento que la principal fuente de dicha contaminación era la importación de maíz transgénico de Estados Unidos en el marco del TLCAN (De Ita, 2012), distribuido mediante las tiendas Diconsa sin advertir las comunidades. En efecto, cabe mencionar que en 2001 un 30\% del maíz cultivado en Estados Unidos era transgénico y en 2010, esta proporción alcanzaba ya un $80 \%$ (De Ita, 2012). Ahora bien, una de las disposiciones del TLCAN permitía justamente la libre circulación de transgénicos bajo el principio de equivalencia sustancial, con lo cual quedó posible su entrada masiva en tierras mexicanas (Colectivo por la autonomía, 2014). Con ello, quedó claro el doble juego del Estado mexicano que, mientras la moratoria estaba todavía en pie, permitía la entrada de maíces transgénicos en territorio nacional, lo que representó una violación de la soberanía nacional y del derecho de los pueblos a autodeterminarse. Hasta la fecha, se han registrado la contaminación de maíces nativos por transgenes en muchos estados de la República Mexicana como Guanajuato, Yucatán, Veracruz o la propia Ciudad de México (Álvarez-Buylla \& Piñeyro, 2013). 


\section{Conclusiones}

En este artículo, se ha mostrado que pensar el desarrollo capitalista en el siglo XX como subsunción real del consumo - en continuidad con la subsunción formal y real del proceso de trabajo al capital que Marx había descrito y conceptualizado durante el siglo XIX - permite considerar el modo de producción capitalista no solamente como un modo de producción en el cual el proceso productivo se encuentra sometido a las necesidades de acumulación de capital sino que, también, su esfera consuntiva está siendo subordinada a tales requerimientos. Además, posibilitó valorar esta dominación sobre el consumo desde su base material cualitativa y no sólo como dominación ideológica. La subsunción del consumo describe una manipulación del contenido material de la riqueza en los cuales los valores de uso tienden a modificar la fisiología de los sujetos, su funcionamiento y sus equilibrios bioquímicos. Esta manipulación es la continuidad histórica lógica de la supeditación del proceso productivo al capital, lo que demuestra la validez de la teoría de Marx para el análisis del capitalismo contemporáneo.

En el ámbito de la alimentación, la subsunción del consumo al capital correspondió a la imposición de un nuevo sistema alimentario propiamente capitalista en el cual el cultivo de los cereales — centrales en las civilizaciones precapitalistas - han sido relegados y/o degradados formal y materialmente. Para el maíz nativo, pilar del sistema alimentario y de la cultura de México y Centroamérica, el presente trabajo concluyó que la producción mexicana de alimentos en su conjunto empezó a estar subordinada al capital en el marco de la Revolución Verde. La pequeña producción campesina fue cada vez más redirigida hacia una producción de tipo industrial favorable a las grandes corporaciones semilleras, lo que implicó una degradación del entorno natural (consumo productivo) así como de los alimentos producidos (consumo final o directo). Este movimiento fue afianzado por las políticas neoliberales que fueron implementadas a finales del siglo XX en México, sobre todo mediante la firma de acuerdos transnacionales que impusieron de facto cambios en los procesos productivos y consuntivos. Además, permitieron la entrada masiva de maíz importado transgénico que fue luego rápidamente objeto de experimentos en el propio territorio nacional. Por las características objetivas de tales plantas genéticamente modificadas, todo el proceso de subsunción real de la producción agrícola y del consumo alimenticio fue redimensionado cualitativamente. Con ello se terminó de construir una agricultura propiamente capitalista centrada en torno a la acumulación de capital. También quedó redondeado el largo proceso de expropiación del campesino que empezó con la llamada acumulación originaria (Marx, 2003) y en el cual el ser humano se encuentra hoy hasta desposeído del núcleo mismo de la vida.

A partir de esta idea, se puede afirmar que el análisis del proceso de degradación del maíz nativo como un proceso de subsunción real del consumo al capital permite desarrollar una perspectiva integral en la cual se enfatiza la continuidad de los fenómenos aquí descritos. Eventos del siglo XX aparentemente aislados se vuelven fases de este proceso en el cual se sometieron paulatinamente los instrumentos de trabajo, las tierras y las semillas del campesino mexicano. Hacer hincapié en esta dinámica histórica continua propicia una mayor posibilidad de reflexión sobre la articulación entre las luchas campesinas a favor de la defensa de los métodos tradicionales de cultivo del maíz nativo con contiendas políticas, económicas y sociales en otros ámbitos de la sociedad. 


\section{Referencias}

Álvarez-Buylla, E. L. y Piñeyro, A. (coord.). (2013). El maíz en peligro ante los transgénicos: un análisis integral sobre el caso de México. UNAM.

Appendini, K., y Liverman, D. (1994). Agricultural policy, climate change and food security in Mexico. Food Policy, 19(2), 149164. https://doi.org/10.1016/0306-9192(94)90067-1

Arslan, A. (2011). Shadow vs. market prices in explaining land allocation: Subsistence maize cultivation in rural Mexico. Food Policy, 36(5), 606614. https://doi.org/10.1016/j.foodpol.2011.05.004

Barreda, A. (2016). El problema histórico de la destrucción ambiental del capitalismo actual. Universidad Nacional Autónoma de México.

Bertran, M. (2017). Domesticar la globalización : alimentación y cultura en la urbanización de una zona rural de México. Anales de Antropología, 51(2), 123-130. https://doi.org/10.1016/j.antro.2017.05.003

Cabrera, S. (2015). Las reformas en México y el TLCAN. Problemas del Desarrollo, 46(180), 77101. https://doi.org/10.1016/s0301-7036(15)72120-6

Cabrera Rebollo, A. G., Hernández Lara, O. G., Zizumbo Villarreal, L., y Arriaga Álvarez, E. G. (2019). Régimen alimentario y biopolítica: problematizando las dietas. Revista mexicana de sociología, 81(2), 417-441. https://cutt.ly/xgK9OJs

Cerros Chávez, J. J. (2017). En busca del cultivo promedio: las repercusiones sociales por la introducción de nuevos cultivos. Acta Sociológica, 73, 123-145. https://doi.org/10.1016/j.acso.2017.08.004

Colectivo por la autonomía, Grupo ETC y GRAIN. (2014). No toquen nuestro maíz. El sistema agroalimentario industrial devasta y los pueblos en México resisten. Editorial Ítaca y GRAIN

Cruz Muñoz, V., Urquizu Rovira, M., Valls Ibáñez, V., Manresa Domínguez J. M., Ruiz Blanco, G., Urquizu Rovira, M., y Toran, P. (2020). Consumo de bebidas refrescantes, deportivas y energéticas en adolescentes. Estudio BEENIS. Anales de Pediatría, 93(4), 242-250. https://doi.org/10.1016/j.anpedi.2020.01.004

Cubero, J. I. (2018). Historia general de la agricultura. Guadalmazán.

Cuevas Mejía, J. de J. (2014). Maíz: alimento fundamental en las tradiciones y costumbres mexicanas. Pasos. Revista de Turismo y Patrimonio Cultural, $\quad 12(2), \quad 425-432$. https://doi.org/10.25145/j.pasos.2014.12.030

De Ita, A. (2012). La defensa internacional del maíz contra la contaminación transgénica en su centro de origen. El Cotidiano, 173, 5765. https://www.redalyc.org/pdf/325/32523131007.pdf

De Ita, A. (2013, 31 de diciembre). El maíz mexicano, 20 años después. La Jornada. https://www.jornada.com.mx/2013/12/31/opinion/005a1pol

Eakin, H., Sweeney, S., Lerner, A. M., Appendini, K., Perales, H., Steigerwald, D. G., Dewes, C. F., Davenport, F., y Bausch, J. C. (2018). Agricultural change and resilience : Agricultural policy, climate trends and market integration in the Mexican maize system. Anthropocene, 23, 4352. https://doi.org/10.1016/j.ancene.2018.08.002

Echeverría, B. (2010). Definición de la cultura. Ítaca.

Echeverría, B. (2017). El discurso crítico de Marx. Ítaca.

Enciso, A. (2007, 30 de octubre). Se exponen a prisión labriegos que siembran maíz transgénico - La Jornada. https://www.jornada.com.mx/2007/10/30/index.php?section $=$ politica\&article $=018 \mathrm{n} 2 \mathrm{pol}$

Gasca, J., y Torres, F. (2014). El control corporativo de la distribución de alimentos en México. Problemas del Desarrollo, 45(176), 133-155. https://doi.org/10.1016/S0301-7036(14)70853-3

González Jácome, A. (2008). El maíz: planta portentosa. Iberóforum. Revista de Ciencias Sociales de la Universidad Iberoamericana, III, 1-17. https://www.redalyc.org/pdf/2110/211015579003.pdf 
González Merino, A. y Castañeda Zavala, Y. (2019). Bioseguridad en biotecnología agrícola en México. La política del Estado y el papel de las organizaciones sociales. Sociológica, 34(97), 183-213. https://cutt.ly/QgKrWoe

González Molina, R. I. (2014). TLCAN : dos décadas de desastres para muchos y grandes beneficios para muy pocos. Suma de Negocios, 5(10), 6768. https://doi.org/10.1016/s2215-910x(14)70011-4

Harvey, D. (2007). Breve historia del neoliberalismo. Akal.

Hernández-Santos, M. I., Mora-Flores, J. S., Martínez-Saldaña, T., Vaquera-Huerta, H., Cruz-León, A., y García-Salazar, J. A. (2006). El Programa de Certificación de Derechos Ejidales y Titulación de Solares Urbanos (PROCEDE): su impacto en Fresnillo, Zacatecas, México. Agrociencia, 40(2), 249-256. https://cutt.ly/1gKrm0Y

Huesca Reynoso, L., López Salazar, R., y Palacios Esquer, M. R. (2016). El Programa de Apoyo Alimentario y la política social integral en la Cruzada contra el Hambre en México. Revista Mexicana de Ciencias Políticas y Sociales, 61(227), 379407. https://doi.org/10.1016/s0185-1918(16)30033-2

Jardí C., Aranda, N., Bedmar, C., Ribot, B., Elias, I., Aparicio, E., y Arija, V. (2019). Ingesta de azucares libres y exceso de peso en edades tempranas. Anales de Pediatría, 90(3), 165-172. https://doi.org/10.1016/j.anpedi.2018.03.018

Jönsson, M. (2016). Blanca Rubio. El dominio del hambre. Crisis de hegemonía y alimentos. Revista mexicana de sociología, 78(2), 317-321. https://cutt.ly/rgKrnb0

Lomelí Vanegas, L., y Vázquez Maggio, M. L. (2016). Cambio estructural y migración. El caso de México. Economía UNAM, 13(39), 325. https://doi.org/10.1016/j.eunam.2016.08.001

Luna Morales, M. E., Luna Morales, E., y Sánchez Martínez, U. (2013). Patrones de producción e impacto científico del Centro Internacional de Mejoramiento de Maíz y Trigo (cimmyt) : 1966-2010. Investigación Bibliotecológica : Archivonomía, Bibliotecología e Información, 27(60), 97124. https://doi.org/10.1016/s0187-358x(13)72545-0

Marx, K. (2003). El capital. RBA Coleccionables.

Marx, K. (2005). La tecnología del capital. Ítaca.

McCarthy, J. (2004). Privatizing conditions of production: trade agreements as neoliberal environmental governance. Geoforum, 35(3), 327341. https://doi.org/10.1016/j.geoforum.2003.07.002

Méndez Rojas, D. A. (2017). Notas para una historia transnacional de la Revolución Verde. Cuadernos americanos 162(4), 137-164. http://www.cialc.unam.mx/cuadamer/textos/ca162-137.pdf

Montesillo-Cedillo, J. L. (2016). Rendimiento por hectárea del maíz grano en México : distritos de riego vs temporal. Economía Informa, 398, 6074. https://doi.org/10.1016/j.ecin.2016.04.005

Moreno, N. M. (2017). Agrohomeopatía como alternativa a los agroquímicos. Revista Médica de Homeopatía, 10(1), 913. https://doi.org/10.1016/j.homeo.2017.04.004

Moreno-Altamirano, L., García-García, J., Soto-Estrada, G., Capraro, S., y Limón-Cruz, D. (2014). Epidemiología y determinantes sociales asociados a la obesidad y la diabetes tipo 2 en México. Revista Médica Del Hospital General De México, 77(3), 114-123. https://doi.org/10.1016/j.hgmx.2014.07.002

Nápoles, P. R. (2017). Neoliberal reforms and Nafta in Mexico. Economía UNAM, 14(41), 7589. https://doi.org/10.1016/j.eunam.2017.06.004

Odisio, J. (2017). Explorando el modelo neoliberal mexicano : ensayo de una reflexión crítica a propósito de la publicación de México cruce de siglos 1970-2014. Economía Informa, 403, 3545. https://doi.org/10.1016/j.ecin.2017.05.003

Picado, W. (2008). Guerra y semillas. Ciencia y geopolítica en los orígenes de la Revolución Verde. Revista de Ciencias Ambientales, 36(2), 46-56. http://dx.doi.org/10.15359/rca.36-2.6

Quist, D., y Chapela, I. H. (2001). Transgenic DNA introgressed into traditional maize landraces in Oaxaca, Mexico. Nature, 414(6863), 541543. https://doi.org/10.1038/35107068 
Rajchenberg S., E. (2017). Reseña del libro Los orígenes del neoliberalismo en México. La escuela austriaca. Economía UNAM, 14(40), 134138. https://doi.org/10.1016/j.eunam.2017.01.006

Rendón-Aguilar, B., Bernal-Ramírez, L. A., Bravo-Avilez, D., y Rocha-Munive, G. (2019). Temporal dynamics of detected transgenes in maize landraces in their center of origin. Revista Mexicana de Biodiversidad, 90(2), 1-12. https:// doi.org/10.22201/ib.20078706e.2019.90.2653

Ribeiro, S. (2008, 29 de marzo). La bioseguridad según Monsanto. La Jornada. https://www.jornada.com.mx/2008/03/29/index.php?section=opinion\&article=023al eco

Ribeiro, S. (2009, 15 de agosto). Verdades ocultas sobre nuestra comida. La Jornada. https://www.jornada.com.mx/2009/08/15/index.php?section=opinion\&article=023a1eco

Romero Hernández, M., Tona Hernández, H., Ruiz Silvera, C., Ávila Ramírez, M., y Alezones Gómez, J. (2018). Efecto de la cosecha mecanizada sobre la calidad del grano de maíz para la recepción y el procesamiento agroindustrial. Tecnología en Marcha, 31(3), 98-109. https://doi.org/10.18845/tm.v31i3.3902

Salas-Porras, A. (2014). Las élites neoliberales en México : ¿cómo se construye un campo de poder que transforma las prácticas sociales de las élites políticas ? Revista Mexicana de Ciencias Políticas y Sociales, 59(222), 279312. https://doi.org/10.1016/s0185-1918(14)70219-3

Sánchez-García, R., Reyes-Morales, H., y González-Unzaga, M. A. (2014). Preferencias alimentarias y estado de nutrición en niños escolares de la Ciudad de México. Boletín Médico del Hospital Infantil de México, 71(6), 358-366. https://doi.org/10.1016/j.bmhimx.2014.12.002

Sandoval Vázquez, D. (2017). Treinta años de transgénicos en México. CECCAM. http://ceccam.org/sites/default/files/30_a\%C3\%B1os_transgenicos.pdf

Sweeney, S., Steigerwald, D. G., Davenport, F., y Eakin, H. (2013). Mexican maize production: Evolving organizational and spatial structures since 1980. Applied Geography, 39, 7892. https://doi.org/10.1016/j.apgeog.2012.12.005

Veraza, J. (2007). Los peligros de comer en el capitalismo. Ítaca.

Veraza, J. (2008). Subsunción real del consumo bajo el capital. Ítaca.

Veraza, J. (2015). Dialéctica histórica de superación de la crisis del marxismo. Pensar desde abajo, 4, 201271. https://cutt.ly/IgKrxiy

Veraza, J. (2017). El sentido Común Mercantil Capitalista y sus fetichismos (a 150 años de la publicación del tomo 1 de El Capital). Teoría y Critica de la Psicología, 9, 1-15. http://www.teocripsi.com/ojs/index.php/TCP/article/view/205/162

Zarazúa-Escobar, J. A., Almaguer-Vargas, G., y Ocampo-Ledesma, J. G.. (2011). El programa de apoyos directos al campo (PROCAMPO) y su impacto sobre la gestión del conocimiento productivo y comercial de la agricultura del Estado de México. Agricultura, sociedad y desarrollo, 8(1), 89-105. https://cutt.ly/SgKrcIx 